\title{
Article \\ Identification of Affecting Factors on the Travel Time Reliability for Bus Transportation
}

\author{
Ahmed Hassan Mohamed ${ }^{1}$, Ibrhim A. I. Adwan ${ }^{1}$, Abobaker G. F. Ahmeda ${ }^{2}$, Hamza Hrtemih ${ }^{1}$, \\ Haitham Al-MSari ${ }^{2}$,* \\ ${ }^{1}$ Dept. of Civil Engineering, Faculty of Engineering and Built Environment, Universiti Kebangsaan Malaysia, Selangor, \\ Malaysia; ibr598@gmail.com; hamzairtemih@gmail.com, qaasim987@gmail.com. \\ ${ }^{2}$ Dept of Civil and Structural Engineering, Higher Institute of Science and Technology Aljufra (HIST), Sokna, Libya; \\ abgribi@gmail.com \\ * Corresponding author: Haitham Al-MSari; haitham.almsari@gmail.com
}

Manuscript received: 10-02-2021, revised: 14-04-2021, accepted: 25-04-2021.

\begin{abstract}
Public bus transit travel time is affected by many factors, including traffic signals and traffic condition. Transit agencies have implemented transit signal priority (TSP) strategies to reduce transit travel time and improve service reliability. However, due to the lack of empirical data, these factors' collective impact and bus travel time strategies have not been studied at the stop-to-stop segment level. This research focuses on the factors affecting travel time reliability, emphasising the variability between operators and the policy implications of such differences. One-way analysis of variance (ANOVA) statistical methods have been used to assess the quality implications of public bus transportation time reliability. This research seeks to investigate the factors affecting the travel time (TT) reliability of bus transport. Studies were conducted along three bus routes serving different areas. Factors strongly related to TT reliability include route length, number of signalised intersections, day of the week, bus stops, departure delays, bus lane, passenger boarding and alighting, weather condition, and fare structure. Based on the proposed model factors affecting TT reliability, it was found that TT is strongly affected by the number of bus stoppings and also the length of the route. The reliability of all three routes during the weekday is low because of delays in departure. The number of signalised intersections along the route affects reliability. Meanwhile, more passengers boarding and paying cash increased the travel time reliability of buses.
\end{abstract}

Keywords: Travel Time Reliability; public transport; influencing Factors; cost; delays; traffic network; Roadworks.

\section{Introduction}

Public transport service is a necessary aspect of life as it provides access to many human activities, such as education, medical care, recreation, etc. [1]. Public transport also helps to keep the environment clean as it reduces the level of gas emission from numerous riders on the roads and helps decongest the roads. Hence, it is considered a cost-effective solution to the environment, land availability, energy and economics [2, 3].

Malaysia is a South-East Asian nation that is considered one of the developing nations of the region. Public transportation is one of the major pillars of the Malaysian economy [3]. Public transportation service has been defined as a shared way of moving people and goods around to meet society's daily basic needs that require access and mobility. The increase in the human population has necessitated expanding the basic transport systems by most countries [4]. Public bus is one of the ways of moving people and goods from one point to the other. However, to considere an essential public transport system, the public bus must offer a reliable service that the passenger can evaluate from various perspectives; this includes assessment in the aspects of reliability and punctuality, which are essential to both the service provider and the public [5- 7]. Travel time reliability refers to measuring the time gap between the expected time of travel and the actual travel time [8]; reliability is low if the time gap between the expected and actual travel times is much. Hence, it is an index to indicate the mean's dispersions due to network uncertainty and perception errors [9]. From the aspect of the mean-variance model and schedule model, it measures the monetary costs for the decline in reliability [10,11]. Although travel time reliability is affected by many factors, most studies have observed travel time reliability on the coming factors, including the route length, number of signalised intersections, etc. The population of Malaysia, as of 2015, is 29,700,386 in 2015 (Malaysia population clock Department of Statistics Malaysia, 2015) [12]. The recent increase in the human population has brought about rapid urbanisation and increased public and private transport systems; this has caused road congestion and negatively affects the bus services' travel time reliability. 
Another issue affecting travel time reliability in public bus transportation is the lack of punctuality and certainty of the scheduled departing and arriving times [13]. Travel time reliability is the most important measure of reliability in the transportation systema sit poses the greatest concern to both service providers and the travelers [14]. Regarding bus services, travel time reliability is important and has been identified as the factor of major concerns to the passengers [15]. Therefore, there is a need to focus on the factors that affect bus travel time reliability and this forms one of the major objectives of this study. The study focuses on the measurement of the time gap between the expected travel time and the actual travel time as a measure of bus travel time reliability.

\section{Data Collection and Survey Findings}

Data were collected from workers in Kuala Lumpur city centre via distributor survey to evaluate the impact of factors affecting the travel time reliability of public bus transportation. In order to meet the study's objectives, a survey needed to collect data relating to the respondent's typical traveller; once the survey had been designed, several businesses and organisations were contacted to request employees' participation in this study. This study chose three different bus routes in which one of that three is RapidKL bus route number 401, a connecting distance of about 29.45 Km from KTM Sergang via Cheras to Bukit Bintang bus hub and vice versa. This bus route was chosen because of its long-distance to figure out many factors affecting travel time reliability Figure 1.

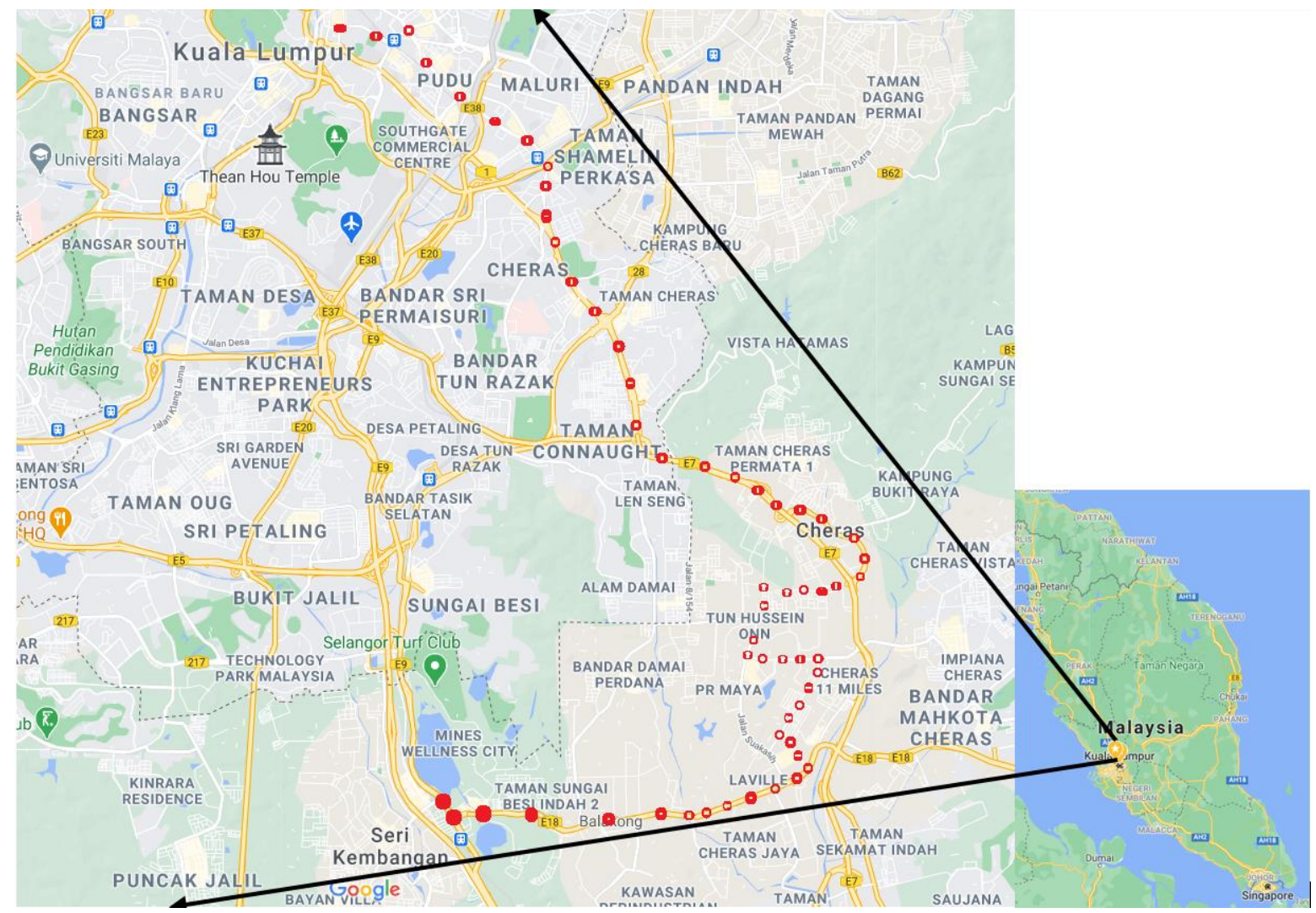

Figure 1. Bus routes 401.

The second bus route is bus route 402, covering a short distance inside Kuala Lumpur, specifically, from LRT Titiwangsa to the KLCC bus stop. This bus route was chosen because it serves in the city centre and shows some difference. Finally, bus number 302 from KLCC bus stop to Tun Razak bus Terminal has the shortest distance compared to the other two, and at the same time, it travels through Kuala Lumpur, which most probably to have concurrent congestion. Figure 2 illustrating bus route 302 from the origin of the destination to the last station. Moreover, this bus route and bus route 402 are both common in that the bus lane was implemented in their ways. 


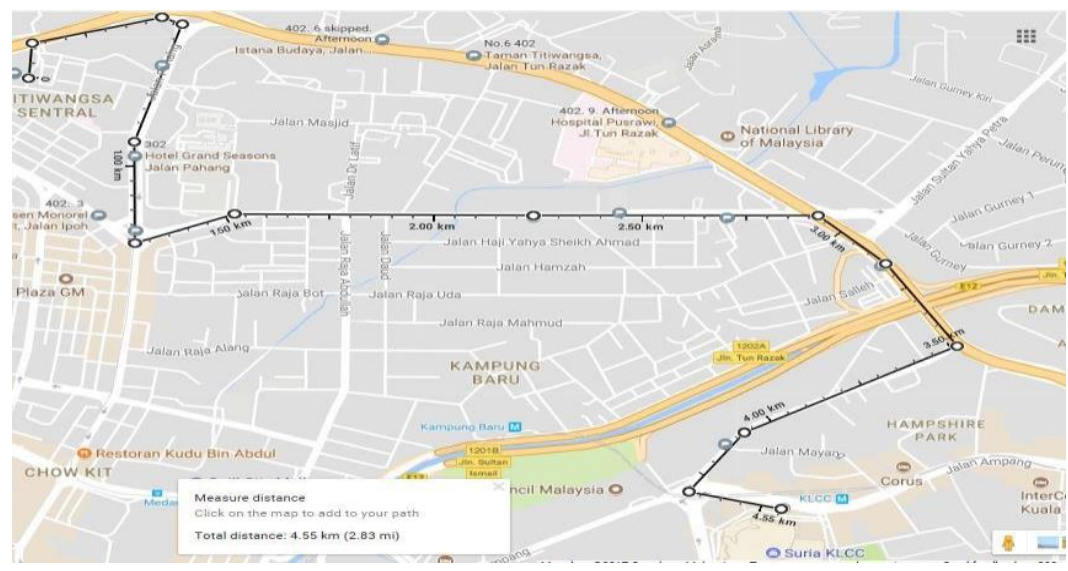

Figure 2. Bus routes 302 .

This study's data was sourced from the RapidKL bus route number 401 from the KTM Serdang bus stop to Bukit Bintang bus hub and vice versa. This bus route covers about $29.5 \mathrm{Km}$ with 43 bus stops. During the rainy days, bus 401 typically meet fewer passengers along its route due to the rain. This study's data collection was done by boarding a bus from the departure point to the terminal for 9 days in April 2018. The route witnesses typically different passenger turnouts during different times of the day (peak period - morning and evening, and off-peak periods - afternoon). A stopwatch was used to calculate the arrival time, dwell time, and departure time of the buses based on phone GPS information. Since there was no bus timetable available for the entire RapidKL Bus Company, however, there is a frequency that shows the departure from starting station to the arrival of the last bus stop and headway showing the time between two buses. According to the bus route's frequency and headway on the RapidKL bus website, it is presenting that there is one bus in every half-hour in bus route 401 during off-peak hours (9:00 - 16:00) and 35 minutes during peak hours (morning and evening).

\subsection{Data Analysis}

This part of the study will be carried out to achieve the stated research. In order to find out the factors affecting travel time reliability, travel time was taken as the dependent variable, and factors found during data collection seem that they affected the bus travel time reliability was taken as independent variables. Analysis of Variance (ANOVA) was used to analyse the difference among group means and their associated procedures. This section will be followed by further analysis by using SPSS statistical software. The descriptive analysis will be displayed to describe the data, and the result will be presented. Table 1 reports the dependent and independent variables of this study.

Table 1. Variables of Travel time and related glossary.

\begin{tabular}{|l|l|l|}
\hline \multicolumn{1}{|c|}{ Variables } & \multicolumn{1}{c|}{ Type } & \multicolumn{1}{c|}{ Description } \\
\hline Travel time & Dependent & $\begin{array}{l}\text { Time spent to travel from origin of the starting } \\
\text { bus stop to the last station }\end{array}$ \\
\hline Route length & Independent & Distance covered during the trip \\
\hline Number of bus stops & Independent & Number of bus stops during the trip \\
\hline Departure delay & Independent & $\begin{array}{l}\text { Time in minutes delayed from the scheduled } \\
\text { time to departure }\end{array}$ \\
\hline Day of the week & Independent & $\begin{array}{l}\text { How the day of the week affects the travel } \\
\text { time }\end{array}$ \\
\hline Passenger Activities & Independent & $\begin{array}{l}\text { Number of passenger boarding and } \\
\text { alighting in every stop }\end{array}$ \\
\hline Number of signals & Independent & Number of traffic signals in every trip \\
\hline Bus Lanes & Independent & Number of bus lanes in each trip \\
\hline Weather condition & Independent & Effect of rain on bus transportation \\
\hline
\end{tabular}


$>$ One-Way Analysis of Variance (ANOVA)

In statistics, one-way analysis of variance (ANOVA) is a technique that can be used to compare the means of two or more samples (using the F distribution). The one-way analysis of variance (ANOVA) is used to determine whether there are any statistically significant differences between the means of two or more independent (unrelated) groups [16]. One-way ANOVA analysis tests the equality of means and variances of the independent variable with dependent variables that include more than two values. This kind of analysis will use the expected and actual departure times. This study will use the following hypothesis.

I. Hypothesis 1: Route length and travel time

$\mathrm{H}_{0}=$ There is no significant difference in route length and travel time.

$\mathrm{H}_{1}=$ There is a significant difference in route length and travel time.

II. Hypothesis 2: Departure delay and travel time

$\mathrm{H}_{0}=$ There is no significant difference between departure delay and travel time.

$\mathrm{H}_{1}=$ There is a significant difference in departure delay and travel

\subsubsection{Bus route 302}

To compare the travel time from the RabidKL website and actual travel time experienced during data collection. Table 2 indicates that bus route number 302 was departing the same as written on their website almost whole the days and it has been seen that only three days showed that it departed later than the expected time. However, the expected arrival time of this route showed more delays than scheduled. Therefore, departure delay is not the factor affecting this bus route; furthermore, other factors will be discussed following sections. Figure 3 shows the scheduled travel and departing time of bus route 302, it also shows the arrival time, and the time the next bus will reach.

Table 2. Actual departure versus expected departure time of bus 302 .

\begin{tabular}{|c|c|c|c|c|}
\hline & \multicolumn{2}{|c|}{ Bus Route 302 (KLCC - Tun Razak Bus Terminal) } & \\
\hline \multirow{2}{*}{ Day } & $\begin{array}{c}\text { Expected } \\
\text { Departure/Arrival }\end{array}$ & $\begin{array}{c}\text { Actual } \\
\text { Departure/Arrival }\end{array}$ & $\begin{array}{c}\text { Departure } \\
\text { Delay (min) }\end{array}$ & $\begin{array}{c}\text { Arrival } \\
\text { Delay } \\
\text { (min) }\end{array}$ \\
\hline Saturday & $01: 55-02: 11$ & $1: 55-02: 11$ & 0 & 0 \\
\hline Sunday & $12: 08-12: 24$ & $12: 08-12: 24$ & 0 & 0 \\
\cline { 2 - 5 } & $15: 08-15: 24$ & $15: 08-15: 25$ & 0 & 1 \\
\hline \multirow{3}{*}{ Monday } & $11: 28-11: 44$ & $11: 28-11: 44$ & 0 & 0 \\
\cline { 2 - 5 } Tuesday & $14: 28-14: 44$ & $14: 32-14: 51$ & 4 & 7 \\
\hline Wednesday & $10: 18-10: 34$ & $10: 24-10: 38$ & 6 & 4 \\
\hline \multirow{3}{*}{ Thursday } & $11: 58-12: 14$ & $11: 58-12: 19$ & 0 & 5 \\
\cline { 2 - 5 } & $14: 38-14: 54$ & $14: 41-15: 02$ & 3 & 8 \\
\hline
\end{tabular}


수 $45.9120 \%=10: 20$

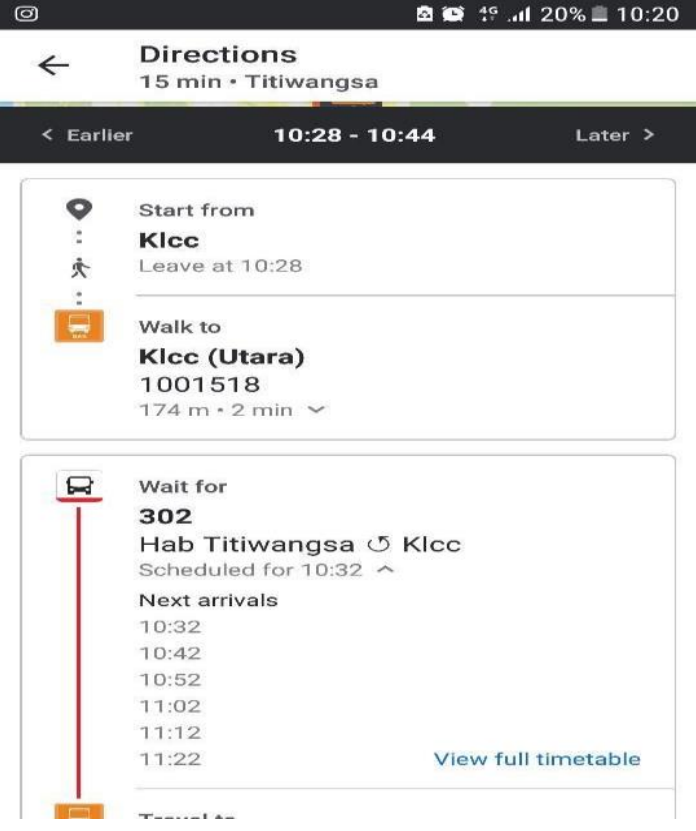

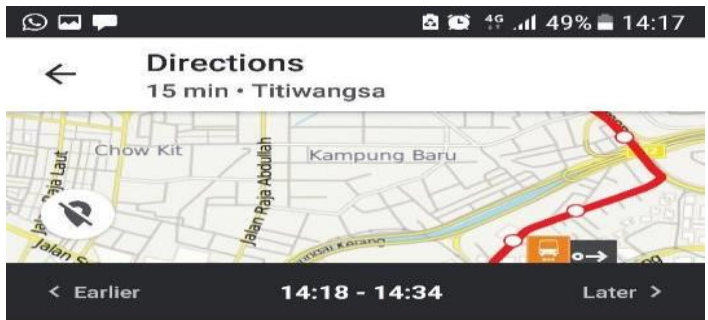

Start from

KIcC

; Leave at 14:18

: Walk to

Klcc (Utara)

1001518

$169 \mathrm{~m} \cdot 2 \mathrm{~min}$ 一

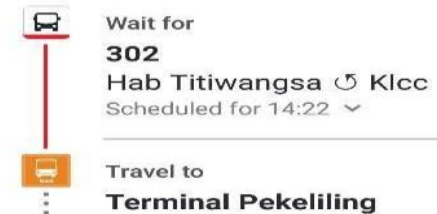

Figure 3. Schedule for buses 302 from RapidKL website.

\subsubsection{Bus route 401}

Likewise, bus route 401 was compared to its expected and actual travel time and also, at the same time, its departure and arrival delay Table 3. The manual and expected travel time was collected from the daily schedule RapidKL website Figure 4.

Table 3. Actual departure versus expected departure time of bus 401.

\begin{tabular}{|l|c|c|c|c|}
\hline \multirow{2}{*}{ Day } & \multicolumn{2}{|c|}{ Bus Route 401 (KTM Serdang - Bukit Bintang) } & \\
\hline \multirow{2}{*}{ Saturday } & Expected Departure/Arrival & $\begin{array}{c}\text { Actual } \\
\text { Departure/Arrival }\end{array}$ & $\begin{array}{c}\text { Departure } \\
\text { Delay (min) }\end{array}$ & Arrival Delay (min) \\
\hline Sunday & $5: 35-10: 54$ & $10: 02-11: 10$ & 27 & 16 \\
\hline \multirow{2}{*}{ Monday } & $5: 00-06: 19$ & $05: 20-06: 30$ & 20 & 11 \\
\cline { 2 - 5 } & $5: 35-10: 54$ & $09: 45-11: 03$ & 10 & 9 \\
\hline Tuesday & $5: 00-6: 19$ & $05: 28-6: 50$ & 28 & 31 \\
\hline Wednesday & $11: 20-12: 39$ & $08: 02-09: 50$ & 2 & 20 \\
\cline { 2 - 5 } & $5: 30-06: 49$ & $05: 41-7: 21$ & 11 & 32 \\
\hline Thursday & $09: 35-10: 54$ & $10: 02-11: 22$ & 27 & 28 \\
\cline { 2 - 5 } & $4: 30-05: 49$ & $04: 47-6: 02$ & 17 & 13 \\
\hline
\end{tabular}




\begin{tabular}{|c|c|c|c|}
\hline \multicolumn{2}{|c|}{ D 401 rapidKL Bus } & \multicolumn{2}{|c|}{401 rapidKL Bus } \\
\hline $\begin{array}{l}\text { Depart } \\
\text { Ktm Serdang }\end{array}$ & $\begin{array}{l}\text { Arrive } \\
\text { Bukit Bintang }\end{array}$ & $\begin{array}{l}\text { Depart } \\
\text { Ktm Serdang }\end{array}$ & $\begin{array}{l}\text { Arrive } \\
\text { Bukit Bintang }\end{array}$ \\
\hline $06: 00$ & $07: 19$ & $12: 30$ & 13:49 \\
\hline $06: 30$ & $07: 49$ & 13:05 & $14: 24$ \\
\hline 07:00 & $08: 19$ & $13: 40$ & 14:59 \\
\hline $07: 30$ & $08: 49$ & 14:15 & $15: 34$ \\
\hline 08:00 & $09: 19$ & $14: 50$ & 16:09 \\
\hline $08: 30$ & $09: 49$ & $15: 25$ & $16: 44$ \\
\hline 09:00 & 10:19 & $16: 00$ & 17:19 \\
\hline $09: 35$ & 10:54 & $16: 30$ & $17: 49$ \\
\hline $10: 10$ & $11: 29$ & 17:00 & 18:19 \\
\hline $10: 45$ & $12: 04$ & $17: 30$ & $18: 49$ \\
\hline $11: 20$ & $12: 39$ & 18:00 & 19:19 \\
\hline $11: 55$ & 13:14 & $18: 30$ & 19:49 \\
\hline
\end{tabular}

Figure 4. Schedule for bus 401 from RapidKL.

In this bus route 401, it was seen that all days appeared to have departure delays; simultaneously, there were arrival delays, and there was no single day with zero delays at all. In order to clarify the reason for the arrival, delays will be discussed in the coming sections.

\subsubsection{Bus route 402}

Table 4 demonstrates the same as above mentioned bus routes, and this bus route has a difference of actual and expected travel time of a minimum a quarter an hour delay for both departure and arrival Figure 5. this route locates in the city centre that might be the cause of both delay. Furthermore, the results will find out in the following sections.

Table 4. Actual departure versus expected departure time of bus 402.

\begin{tabular}{|c|c|c|c|c|}
\hline \multirow{2}{*}{ Day } & \multicolumn{2}{|c|}{ Bus Route 402 (LRT Titiwangsa - KLCC) } & \\
& $\begin{array}{c}\text { Expected } \\
\text { Departure/Arrival }\end{array}$ & $\begin{array}{c}\text { Actual } \\
\text { Departure/Arrival }\end{array}$ & $\begin{array}{c}\text { Departure } \\
\text { Delay (min) }\end{array}$ & $\begin{array}{c}\text { Arrival Delay } \\
\text { (min) }\end{array}$ \\
\hline Saturday & $14: 30-14: 49$ & $14: 48-15: 07$ & 18 & 18 \\
\hline Sunday & $16: 00-16: 19$ & $16: 15-16: 31$ & 15 & 12 \\
\hline Monday & $12: 00-12: 19$ & $12: 15-12: 36$ & 15 & 17 \\
\cline { 2 - 5 } & $15: 00-15: 19$ & $15: 18-15: 39$ & 18 & 20 \\
\hline Tuesday & $10: 30-10: 49$ & $10: 42-11: 03$ & 12 & 14 \\
\hline Wednesday & $12: 00-12: 19$ & $12: 15-12: 35$ & 15 & 16 \\
\hline Thursday & $12: 00-12: 19$ & $12: 28-12: 44$ & 28 & 25 \\
\cline { 2 - 5 } & $15: 00-15: 19$ & $15: 16-15: 37$ & 16 & 18 \\
\hline
\end{tabular}




\begin{tabular}{|c|c|c|c|}
\hline 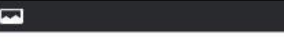 & $\Delta \alpha \bar{z} .1151 \%=09: 40$ & 묠 & 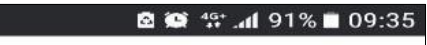 \\
\hline D 402 & rapidKL Bus & $\$ 402$ & rapidKL Bus \\
\hline $\begin{array}{l}\text { Depart } \\
\text { Lrt Titiwangsa }\end{array}$ & $\begin{array}{l}\text { Arrive } \\
\text { KIcc (Utara) }\end{array}$ & $\begin{array}{l}\text { Depart } \\
\text { Lrt Titiwangsa }\end{array}$ & $\begin{array}{l}\text { Arrive } \\
\text { Klcc (Utara) }\end{array}$ \\
\hline $06: 00$ & $06: 19$ & 12:00 & 12:19 \\
\hline $06: 30$ & $06: 49$ & $12: 30$ & $12: 49$ \\
\hline 07:00 & 07:19 & 13:00 & 13:19 \\
\hline $07: 30$ & $07: 49$ & 13:30 & 13:49 \\
\hline 08:00 & 08:19 & 14:00 & 14:19 \\
\hline $08: 30$ & $08: 49$ & 14:30 & $14: 49$ \\
\hline $09: 00$ & $09: 19$ & 15:00 & 15:19 \\
\hline $09: 30$ & $09: 49$ & 15:30 & 15:49 \\
\hline 10:00 & 10:19 & $16: 00$ & 16:19 \\
\hline $10: 30$ & 10:49 & 16:30 & $16: 49$ \\
\hline 11:00 & 11:19 & 17:00 & 17:19 \\
\hline $11: 30$ & 11:49 & $17: 30$ & $17: 49$ \\
\hline
\end{tabular}

Figure 5. Schedule for bus 402 from RapidKL.

During data collection, it has been observed that most of the buses showed a delay in the departure, comparing scheduled departure time and actual departure seen in the field. Figure 6 illustrates the summary of the average departure delays in each bus. Bus route 302 showed the slightest average delay of 1.625 minutes during the whole trip compared to other bus routes 402 and 401, which appeared almost the same results of 16.325 minutes and 17.75 minutes, respectively. The delay at the first stations contributed to taking part in the reasons to arrive later than planned time. Besides, it will also cause unreliability.

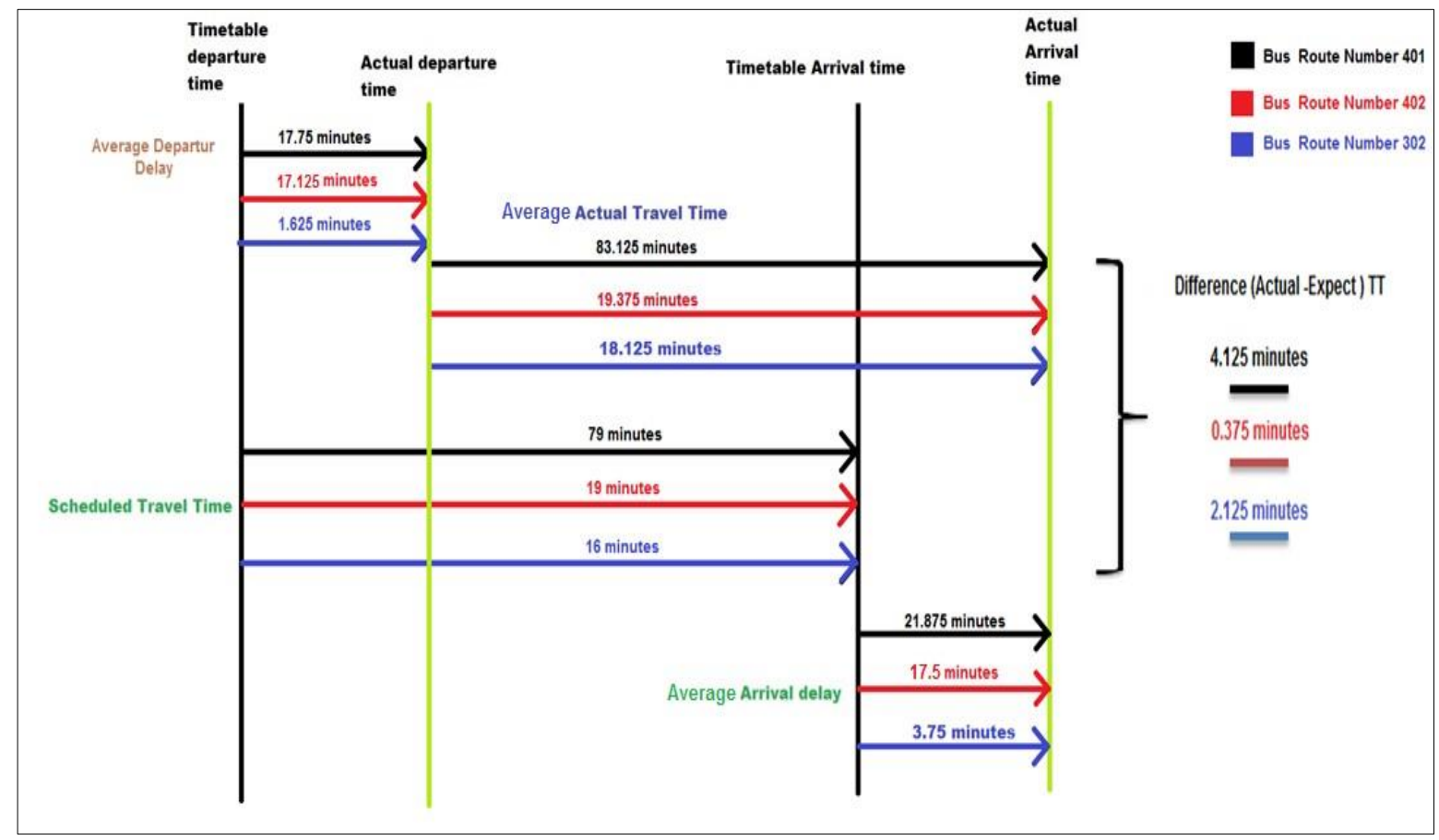

Figure 6. Actual departure versus expected departure time. 


\section{Characteristics of the bus in time reliability}

When estimating and predicting the bus travel time reliability of public bus transportation, it is essential to understand its public bus transportation characteristic. In this section, the factors affecting bus travel time will be studied as Table 5 shows factors affecting travel time reliability of public bus transportation.

Table 5. Factors affect bus travel time reliability.

\begin{tabular}{|c|c|c|}
\hline \multicolumn{2}{|c|}{ Primary factors } & Other factors \\
\hline Route length & Number of traffic signals & Driver Behaviours \\
\hline Number of bus stops & Bus Lanes & \\
\hline Day of the week & Dwell Time & \\
\hline Departure delays & Weather Condition & \\
\hline
\end{tabular}

\subsection{Route Length}

Route length is one of the most important factors that are highly associated with bus travel time. Travel distance from origin to destination corresponds to the travel time on the bus. In order to determine the effect of travel distance on the bus travel time reliability, it was chosen three different bus routes with different distances. According to the hypothesis given in the methodology, $\mathrm{H}_{0}=$ there is no significant difference in route length on travel time variability and $\mathrm{H} 1=$ there is a significant difference in route length on travel time variability. Analysis of variance (ANOVA) was used to test whether to reject the null hypothesis or not. Based on Table 6, p-value is 0.000 and less than $\alpha=0.05$. Therefore the null hypothesis is rejected. Additionally, there is a significant difference in route length on travel time.

Table 6: ANOVA test of Route length with travel time.

\begin{tabular}{|l|l|c|c|c|c|}
\hline & Sum of Squares & df & Mean Square & F & Sig. \\
\hline Between Groups & 19780.083 & 2 & 9890.042 & 212.526 & .000 \\
\hline Within Groups & 977.250 & 21 & 46.536 & & \\
\hline Total & 20757.333 & 23 & & & \\
\hline
\end{tabular}

As stated in the methodology, bus route 401 has longer distances, $29.5 \mathrm{Km}$ compared to bus routes 402 and 302 which are $5.85 \mathrm{Km}$ and $4.55 \mathrm{Km}$, respectively. As it was expected, bus route 401 completed the most extended trips and observed it arrived at its destination late most of the trips. In other words, this implies that the shorter the routes, the more likely they would be reliable, as shown in Figure 7. Bus route 401 covered $29.5 \mathrm{~km}$ and spent an average of 83.125 minutes while 402 crossed $5.85 \mathrm{~km}$ took 19.38 minutes and least one with the shortest distance bus route 302 ended $4.55 \mathrm{~km}$ with 18.125 minutes, similarly to researchers studies [17-19,22]. They were expected that the travel time increases with the increase in route length.

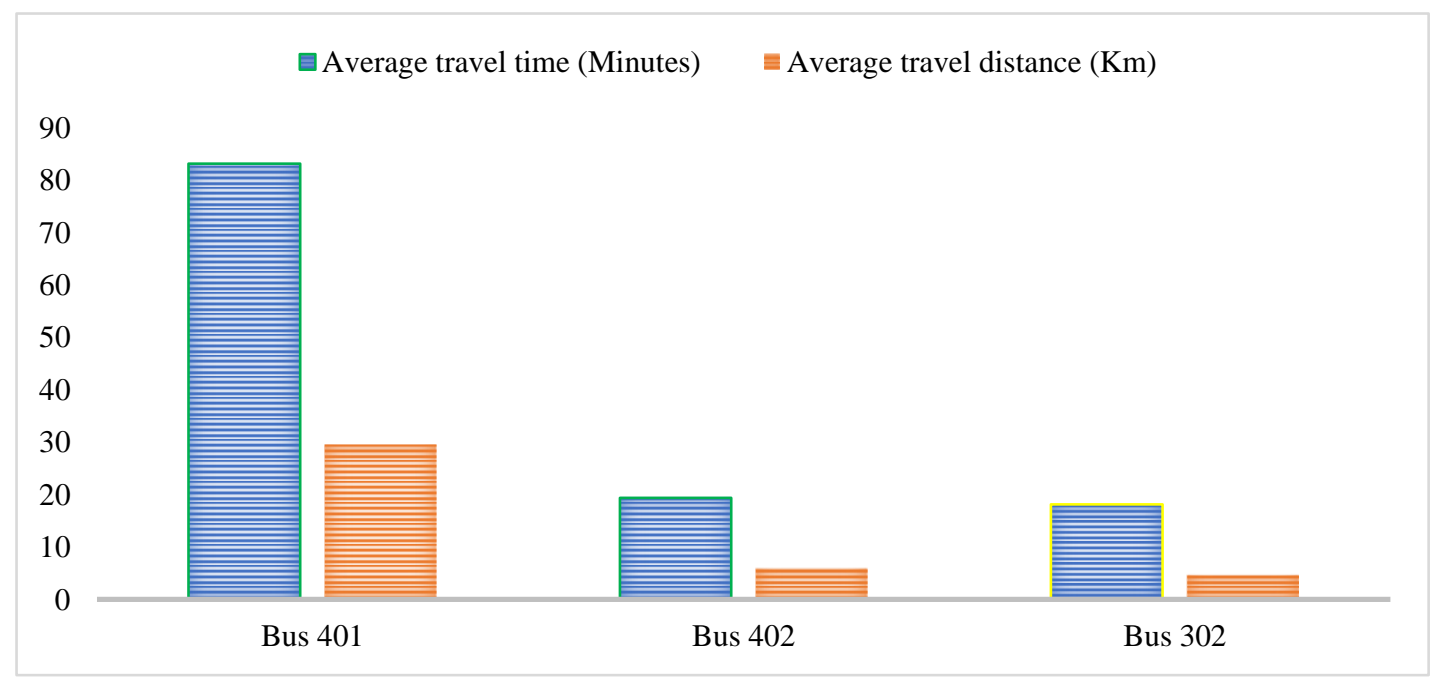

Figure 7. Route Length. 


\subsection{Number of bus stops}

The number of bus stops is another factor affecting bus travel time reliability. Each bus route has its bus numbers; the longer the distance, the more bus stops it would have. By comparing these three bus routes specified in this study, route 401 has 43 bus stops, while 402 and 302 have 9 and 7 bus stops, respectively, with signboard, was written bus route numbers on the bus stop. During collecting data, it was observed that the driver stopped unregistered bus stops when he sees a passenger waving a hand to stop. However, this situation will influence the reliability of the bus. Bus route names were downloaded from RapidKL in each route; therefore, these signboards were to conform to it. This effect was seen all the three bus routes and consequently, it increased the travel time and at the same time reduced the reliability of the bus. For example, bus route 402 has 9 bus stops and yet, it was observed that there was a minimum of one additional bus stop on each trip and a maximum of 4 different bus stations.

Furthermore, in terms of dwell time delay caused by stopping non-bus stop, there were averages of 20 seconds spend passenger boarding and alighting. Figure 8 shows an average number of unregistered bus stops along the bus route (Nonbus stops) stopped by the driver. Every additional bus stop will increase travel time and, at the same time, decrease reliability.

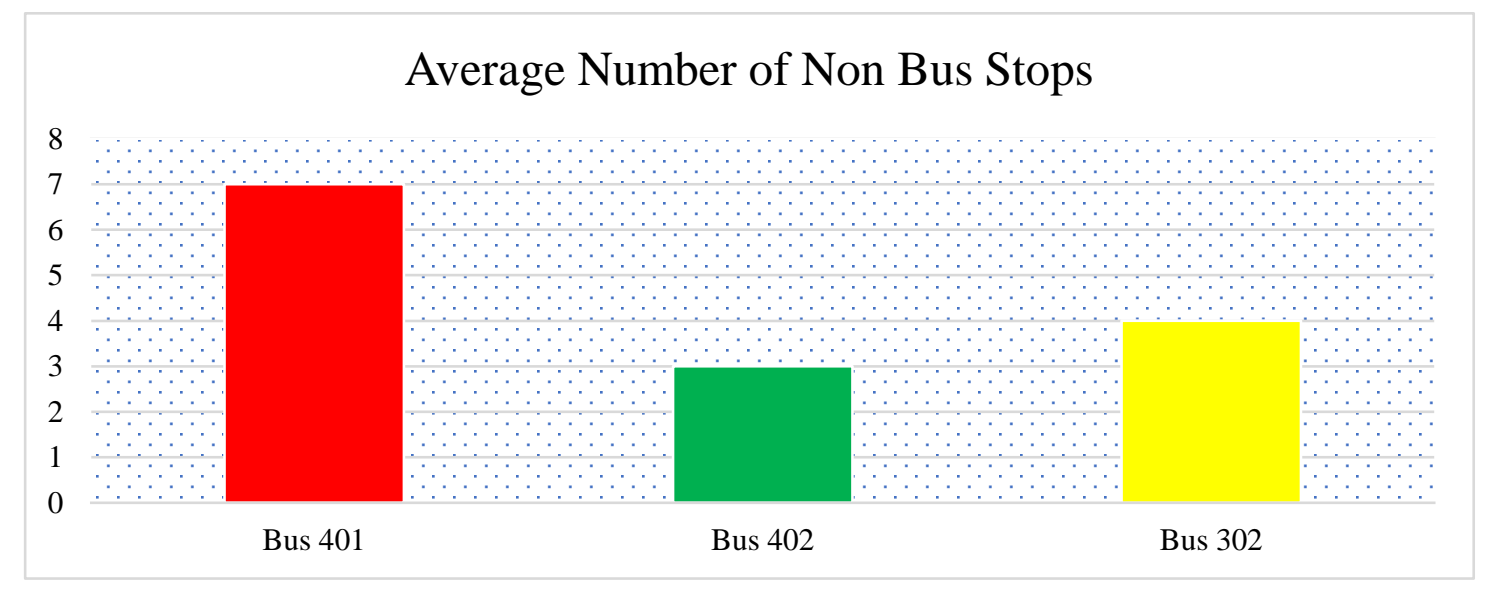

Figure 8. Numbers of Bus Stops.

By comparison to previous researchers [16-20], they all found that additional travel time is associated with each different bus stop range between 5 seconds to 26 seconds. Similarly, other researchers came up with different methods by using the number of scheduled bus stops as the variable, and they found an average of 5 seconds to 13 seconds increase in travel time for each additional bus stop [21, 22]. Thus, other researcher found that unregistered bus stops have more effect on bus travel time than registered bus stops because buses may skip some bus stops during each trip [17]. Previous studies have noted that the increase in bus travel times is usually caused by the intermittent stops at the different bus stops; this time increase ranges typically from 5 seconds to 26 seconds [16-20]. Some studies have also devised using the number of scheduled bus stops as one of the variables to contribute to delayed bus arrival times. These studies noted that each additional bus stop adds about 5 seconds to 13 seconds to the expected travel time [21, 22]. The effect of unregistered bus stops on bus travel time was also more significant than that of the registered bus stops because the busses may skip some recognised bus stops during each trip [17].

\subsection{Departure delay}

Departure time plays an essential role in bus arrival time and reliability. First, to check the relationship between departure delay and travel time using the ANOVA test, there is a significant difference since the p-value is less than 0.05 Table 7. 
Table 7. ANOVA test of Travel time with Departure delay.

\begin{tabular}{|c|c|c|c|c|c|}
\hline & Sum of Squares & df & Mean Square & F & Sig. \\
\hline Between Groups & 21564.158 & 14 & 1540.297 & 7.169 & .003 \\
\hline Within Groups & 1933.800 & 9 & 214.867 & & \\
\hline Total & 23497.958 & 23 & \multicolumn{3}{l}{} \\
\hline
\end{tabular}

Moreover, it was observed that bus routes 401 and 402 departure later than the planned time written on the RabidKL bus website, so this travel time variability could be one of the main factors that can cause travel time unreliability and, at the same time, can cause delay of arriving on time. Figure 8 shows that bus route number 401 appeared to have delays at all first stations; by the same token, this delay was affected the subsequent bus stops and concurrently affected the whole scheduled travel time. Not only bus route 401 showed the delays, but also 402 had shared the same characteristics. However, bus route 302 has seen departing almost on time during the whole week with an average of 1.625 minutes delay, but unfortunately, it was seen more arrival delays, so in this case, we can conclude that the arrival delay is caused factors, not departure delay.

\subsection{Dwell Time}

Dwell time is another factor affecting travel time reliability. It is the time required to serve passengers at the busiest door, plus the time required to open and close the doors. Dwell time is affected by passenger activity, fare payment collection method, driver experience and time of the day.

\subsection{Passenger Boarding and Alighting}

Passenger activities were also found to have a significant impact on bus travel time; for instance, each passenger boarding was found to increase the bus travel time by an average of 5.5 seconds if the passengers use the front door and paid cash, whereas those that used the intelligent card payment system require about 3.5 seconds on the average. Passengers alighting the bus also increased the travel time by about 2 seconds, but the type of payment did not affect the travel time. According to previous studies, the passenger boarding time was averaged $3.4-3.7$ seconds, while the time to alight ranged from $0.4-1.5$ seconds $[17,23,24]$.

\subsection{Fare Payment}

Fare payment time is the required time for a passenger to complete the payment of the prescribed amount for each trip and it is believed that different fare payment methods have different impacts on the dwell time. Cash payments that demand giving change to the passenger typically have the highest impact on the dwell time, while smart card payment using TouchNgo \& RapidKL Cards (though not always shown for all trips) has little impact on the dwell time compared to a cash payment that requires giving change to the passenger. However, the comparing the impact of different payment systems on the dwell time shown in Table 8, detailing the total number of passengers who used Smart Card and cash and the time spent on each fare payment method.

Table 8. The number of passengers paid cash.

\begin{tabular}{|c|c|c|c|c|c|}
\hline \multicolumn{2}{|c|}{ Bus Route 401} & \multicolumn{2}{|c|}{ Bus Route 402} & \multicolumn{2}{|c|}{ Bus Route 302} \\
\hline $\begin{array}{l}\text { No of } \\
\text { passengers } \\
\text { used cash }\end{array}$ & $\begin{array}{l}\text { No of } \\
\text { passengers used } \\
\text { Card }\end{array}$ & $\begin{array}{cr}\text { No of } \\
\text { passengers used } \\
\text { cash }\end{array}$ & $\begin{array}{l}\text { No of } \\
\text { passengers used } \\
\text { Card }\end{array}$ & $\begin{array}{l}\text { No of } \\
\text { passengers used } \\
\text { cash }\end{array}$ & $\begin{array}{l}\text { No of } \\
\text { passengers used } \\
\text { Card }\end{array}$ \\
\hline 31 & 5 & 8 & 5 & 16 & 2 \\
\hline 39 & 15 & 4 & 1 & 32 & 1 \\
\hline 51 & 4 & 9 & 2 & 5 & 7 \\
\hline 29 & 16 & 8 & 6 & 12 & 11 \\
\hline 68 & 6 & 3 & 6 & 3 & 3 \\
\hline 31 & 12 & 1 & 1 & 6 & 8 \\
\hline 15 & 10 & 3 & 4 & 7 & 8 \\
\hline 56 & 19 & 6 & 3 & 19 & 8 \\
\hline $\begin{array}{c}\text { Total } \\
\mathbf{3 2 0} \\
\end{array}$ & $\begin{array}{c}\text { Total } \\
87 \\
\end{array}$ & $\begin{array}{c}\text { Total } \\
42 \\
\end{array}$ & $\begin{array}{c}\text { Total } \\
28 \\
\end{array}$ & $\begin{array}{c}\text { Total } \\
100 \\
\end{array}$ & $\begin{array}{c}\text { Total } \\
48 \\
\end{array}$ \\
\hline $\begin{array}{c}\text { Percentage } \\
79 \%\end{array}$ & $\begin{array}{c}\text { Percentage } \\
21 \%\end{array}$ & $\begin{array}{c}\text { Percentage } \\
60 \%\end{array}$ & $\begin{array}{c}\text { Percentage } \\
40 \%\end{array}$ & $\begin{array}{c}\text { Percentage } \\
68 \%\end{array}$ & $\begin{array}{c}\text { Percentage } \\
32 \%\end{array}$ \\
\hline
\end{tabular}


Table 9 compares to time spent by passengers who used Card with passengers who used cash, and it was taken the total number from each to get the exact difference. For example, bus route 401 had 87 passengers used Card and therefore, 320 passengers used cash was picked up and then multiplied time spent each (5.5 seconds for cash payment and 3.5 for Card). Finally, there are 24 minutes of difference in cash payment with card users in bus route 401. Similarly, bus routes 402 and 302 were found 2.3 minute and 6.2 minutes, respectively. On the other hand, the passengers who used smart cards were not even reached $50 \%$ of the total travellers paid cash. Therefore, using smart cards will decrease the dwell time.

Table 9. Comparison between cash and card users.

\begin{tabular}{|c|c|c|c|c|c|}
\hline \multicolumn{2}{|c|}{ Bus Route 401 } & \multicolumn{2}{c|}{ Bus Route 402 } & \multicolumn{2}{c|}{ Bus Route 302 } \\
\hline $\begin{array}{l}\text { No. of } \\
\text { passengers used } \\
\text { cash }\end{array}$ & $\begin{array}{l}\text { No. of passengers } \\
\text { used Card }\end{array}$ & $\begin{array}{l}\text { No. of passengers } \\
\text { used cash }\end{array}$ & $\begin{array}{l}\text { No. of passengers } \\
\text { used Card }\end{array}$ & $\begin{array}{l}\text { No. of passengers } \\
\text { used cash }\end{array}$ & $\begin{array}{l}\text { No. of passengers } \\
\text { used Card }\end{array}$ \\
\hline 320 & 87 & 42 & 28 & 100 & 48 \\
\hline $29(\mathrm{~min})$ & $5(\mathrm{~min})$ & $3.9(\mathrm{~min})$ & $1.6(\mathrm{~min})$ & $9(\mathrm{~min})$ & $2.8(\mathrm{~min})$ \\
\hline \multicolumn{2}{|c|}{$24(\mathrm{~min})$} & \multicolumn{2}{|c|}{$2.3(\mathrm{~min})$} & & \\
\hline
\end{tabular}

\subsection{Weather condition}

Compared to the good weather, the rain showed a decrease in travel time. In this study, it was observed lower travel time on rainy days. Although it only rained two days during the data collection process in route 401, both days were common in less travel time than other normal days. Undoubtedly, during the rain, the travel speed was less than the actual because of the fewer gaps between traffic, but it showed less passenger demand and skipped more bus stops since no passengers were available. On the other hand, studies from other researchers showed the opposite of what was found in this study regarding the rainy weather: the rain increased travel time due to the lower speed for safety [26].

\section{Results and Discussion}

This section discussed the comparison of scheduled travel time and actual travel time and affects the travel time reliability of bus transportation, as shown in Table 10, summarising the factors that have affected each bus under study. However, the brief of each registered factor.

Table 10: Summary of factors affecting each bus.

\begin{tabular}{|l|c|c|c|}
\hline \multicolumn{1}{|c|}{ Factors } & Route 401 & Route 402 & Route 302 \\
\hline Route Length & $\square$ & & \\
\hline Number of Bus Stops & $\square$ & & \\
\hline Departure Delay & $\square$ & $\square$ & \\
\hline Day of the week & $\square$ & $\square$ & $\square$ \\
\hline Dwell Time & $\square$ & $\square$ & $\square$ \\
\hline Number of Signals & $\square$ & $\square$ & $\square$ \\
\hline Bus Lane & $\square$ & & \\
\hline Weather Condition & & & \\
\hline
\end{tabular}

As discussed earlier, bus route 401, the longer the route, the longer the travel time, and the less reliable it will become. The number of bus stops is another factor; the more bus stops more travel time. However, that will lead to more travel time. Besides, unregistered bus stops played the main part of unreliability and affected all three bus routes. Day of the week was seen to affect travel time; during data collection, weekdays were showed higher travel time than weekends. However, weekdays appeared more unreliable. More dwell time resulted in more travel time and the main effect to decrease the dwell time is by decreasing passenger boarding and alighting time by encouraging using smart cards. Most of the bus routes were experienced being common on the effect of passenger boarding and fare payment delays. Departure delay was the most sensitive factor, which was daily expected to happen. By comparing the day-to-day schedule from the RapidKL website showing the frequency and headway of the buses, this factor was common in routes 401 and 402, while 302 showed the lowest average departure delays. Bus routes 401 travelled through residential to the city centre, while the experienced different lanes, which one lane was the minimum and five lanes was the maximum. Therefore, the fewer the number of lanes, the longer travel time would it take. 
On the other hand, bus routes 402 and 302 were both serving in the city centre where the bus lane has implemented part of the route, and this bus lane eased to have lower travel time. Finally, the weather condition is the last factor that is being discussed in this study. Although during data collection, only route number 401 was experienced rainy weather; therefore, it showed lower travel time during rain because of less passenger demand and at the same time more skipping empty bus stops.

\section{Conclusion}

This study determined the factors affecting the reliability of public bus transportation has deeply explored to find out RabidKL bus travel time besides the major influential factors that affect bus transportation travel time. A field survey and observation was carried out at three different bus routes, namely Bus routes 401, 402 and 302 , to increase the chance of getting different scenarios. Numbers of factors have been registered during this research which is: route length, number of bus stops, number of traffic signals, departure delays, day of the week, bus lane and weather condition. Departure delay was booked as the main factor. Several traffic signals were the next sensitive; route length was found significantly associated with travel time variability. The number of bus stops showed a significant effect. Simultaneously, the week's day appeared significantly different during data collection days, and finally, the bus lane was seen significantly affecting travel time variability. Some of these factors mentioned above were common in all the three bus routes, while the rest were only specified only for one bus route. For example, several passenger boarding and alighting day of the week were all seen commonly affecting travel time reliability of the three bus routes. However, route length, bus lane, bus stops, and weather condition only affected bus route 401, while departure delay affected bus routes 401 and 402 . Therefore, the results showed that bus route 302 is more reliable than the other two bus routes, and even though bus route 402 is unreliable after seeing the results whatsoever, it is better than bus route 401 , which is unreliable.

Conflict of interest: The authors declare no conflict of interest.

\section{References}

[1] E. Hadaway, "Public Transportation," 2017.

[2] Z. Liu, Y. Yan, X. Qu, and Y. Zhang, "Bus stop-skipping scheme with random travel time," Transportation Research Part C: Emerging Technologies, vol. 35, pp. 46-56, 2013.

[3] M. Rojo, H. Gonzalo-Orden, L. dell'Olio, and A. Ibeas, "Modelling gender perception of quality in interurban bus services," Proceedings of the Institution of Civil Engineers - Transport, vol. 164, no. 1, pp. 43-53, 2011.

[4] K. Ambak, K. K. Kasvar, B. D. Daniel, J. Prasetijo, and A. R. Abd Ghani, "Behavioral Intention to Use Public Transport Based on Theory of Planned Behavior," MATEC Web of Conferences, vol. 47, p. 03008, 2016.

[5] V. J. Joseph, "Punctuality Index for the City Bus Service," International Journal of Engineering Research, vol. 4, no. 4, pp. 206-208, 2015.

[6] N. Yaakub and M. Napiah, "Quality of Service and Passenger's Perception - A Review on Bus Service in Kota Bharu,” International Journal of Civil \& Environmental Engineering, vol. 11, no. 5, p. 9, 2011.

[7] A. Rahul Raoniar, Amudapuram Mohan Rao and S. Velmurugan, "Public Transport Performance Evaluation Techniques -A Review," no. May, 2015.

[8] B. MEHRAN and H. NAKAMURA, "Considering Travel Time Reliability and Safety for Evaluation of Congestion Relief Schemes on Expressway Segments," IATSS Research, vol. 33, no. 1, pp. 55-70, 2014.

[9] K. A. Small, "Valuation of travel time," Economics of Transportation, vol. 1, no. 1-2, pp. 2-14, 2012.

[10] G. De Jong, Y. Tseng, M. Kouwenhoven, E. Verhoef, and J. Bates, "The Value of Travel Time and Travel Time Reliability Survey Design Final report Prepared for The Netherlands Ministry of Transport, Public Works and Water Management," no. July, 2007.

[11] C. Carrion and D. Levinson, "Value of travel time reliability: A review of current evidence," Transportation Research Part A: Policy and Practice, vol. 46, no. 4, pp. 720-741, 2012.

[12] A. R. Ismail, "A DESCRIPTIVE ANALYSIS OF FACTORS CONTRIBUTING TO BUS DRIVERS' PERFORMANCES WHILE DRIVING: A CASE STUDY IN MALAYSIA," International Journal of Automotive and Mechanical Engineering (IJAME, vol. 11, no. June, pp. 2430-2437, 2015.

[13] Y. Noorfakhriah and M. Napiah, "Public Transport: Punctuality Index for Bus Operation," World Academy of Science, Engineering and Technology 60, vol. 60, 2011.

[14] A. M. El-geneidy, M. Building, and J. Horning, "Analyzing Transit Service ReliabilityUsing Detailed Data from Automatic Vehicular Locator Systems," Journal of Advanced Transportation, vol. 45, pp. 66-79, 2011.

[15] E. Diab, M. Badami, and A. El-Geneidy, "Bus Transit Service Reliability and Improvement Strategies : Integrating the Perspectives of Passengers and Transit Agencies In North America Ehab Diab , Madhav Badami, and Ahmed El-Geneidy School of Urban Planning Email :," vol. 23, pp. 1-34, 2015. 
[16] J. Howell and J. Pearce, Civil society \& development: A critical exploration. Lynne Rienner Publishers, 2002.

[17] E. I. Diab and A. M. El-Geneidy, "Understanding the impacts of a combination of service improvement strategies on bus running time and passenger's perception," Transportation Research Part A: Policy and Practice, 2012.

[18] W. Feng and M. A. Figliozzi, "Conventional vs Electric Commercial Vehicle Fleets: A Case Study of Economic and Technological Factors Affecting the Competitiveness of Electric Commercial Vehicles in the USA," Procedia - Social and Behavioral Sciences, 2012.

[19] C. Slavin, W. Feng, M. Figliozzi, and P. Koonce, "Statistical study of the impact of adaptive traffic signal control on traffic and transit performance," Transportation Research Record, 2013.

[20] J. G. Strathman, T. J. Kimpel, K. J. Dueker, R. L. Gerhart, and S. Callas, "Evaluation of transit operations: Data applications of Tri-Met's automated bus dispatching system," Transportation, 2002.

[21] A. M. El-Geneidy, P. Tétreault, and J. Surprenant-Legault, "Pedestrian access to transit: Identifying redundancies and gaps using a variable service area analysis," 89th Transportation Research Board Annual Meeting, 2010.

[22] A. M. El-Geneidy, J. Horning, and K. J. Krizek, "Analyzing transit service reliability using detailed data from automatic vehicular locator systems," Journal of Advanced Transportation, 2011.

[23] A. El-Geneidy, D. Levinson, E. Diab, G. Boisjoly, D. Verbich, and C. Loong, "The cost of equity: Assessing transit accessibility and social disparity using total travel cost," Transportation Research Part A: Policy and Practice, 2016.

[24] R. L. Bertini and A. M. El-Geneidy, "Modeling transit trip time using archived bus dispatch system data," Journal of Transportation Engineering, 2004.

[25] K. Dueker, T. Kimpel, J. Strathman, and S. Callas, "Determinants of Bus Dwell Time," Journal of Public Transportation, 2004.

[26] Z. L. Ma, L. Ferreira, M. Mesbah, and A. T. Hojati, "Modeling bus travel time reliability with supply and demand data from automatic vehicle location and smart card systems," Transportation Research Record, 2015. 